\title{
Likovni život u Dubrovniku između 1850. i 1945. godine
}

\section{Žaja Vrbica, Sanja}

Source / Izvornik: Institucije povijesti umjetnosti : zbornik 4. kongresa hrvatskih povjesničara umjetnosti, 2019, 259 - 265

Conference paper / Rad u zborniku

Publication status / Verzija rada: Published version / Objavljena verzija rada (izdavačev PDF)

https://doi.org/10.31664/z4khpu.34

Permanent link / Trajna poveznica: https://urn.nsk.hr/urn:nbn:hr:254:218894

Rights / Prava: Attribution 4.0 International/Imenovanje 4.0 međunarodna

Download date / Datum preuzimanja: 2023-04-26

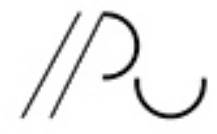

INSIITUTR ZA POVIJEST UMJETNOST
Repository / Repozitorij:

PODEST - Institute of Art History Repository

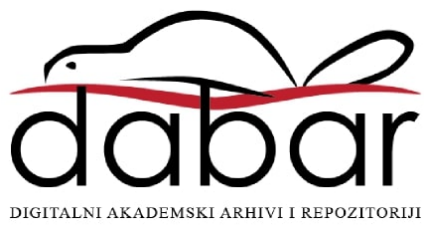




\section{Likovni život u Dubrovniku između I850. i r945. godine}

Likovni život u Dubrovniku tijekom razdoblja između I85o. i I945. godine možemo pratiti slijedom različitih izložbi, po prvim pojavama likovnih kritika, akcijama organiziranja prvih muzejskih institucija i njihovim realizacijama. Povijest Domorodnog muzeja otvorena I872. godine i procesi koji su vodili njegovu otvaranju bili su predmet brojnih istraživačkih studija. Umjetnička galerija otvorena I945. godine također je bila u fokusu znanstvenih istraživanja, no osnivanjem tih institucija ne započinje likovni život Dubrovnika novijeg doba. Tijekom tog razdoblja bilježimo niz izložbi u različitim javnim i privatnim prostorima, članke autora različitih profesija, entuzijasta i stručnjaka koji su tekstovima, analizama dubrovačkih umjetničkih prilika i potreba, istraživanjima i organiziranjem izložbi te pisanjem likovnih prikaza intenzivno poticali i podupirali likovni život grada.

Do sada to razdoblje dubrovačke likovne baštine nije dovoljno istraženo, općenito je malo studija o umjetnosti rg. stoljeća u Dubrovniku, dok je 20. stoljeće češće razmatrano u različitim publikacijama. O prvoj polovini Ig. stoljeća pišu Kruno Prijatelj, ${ }^{1}$ Grgo Gamulin, ${ }^{2}$ Vinicije Lupis, ${ }^{3}$ Tonko Maroevićc ${ }^{4}$ i drugi, no o drugoj polovini stoljeća vrlo je malo objavljenih materijala. Izložba priređena u Umjetničkoj galeriji u Dubrovniku I978. godine Sto godina moderne umjetnosti u Dubrouniku ${ }^{5}$ donosi više podataka o tom razdoblju, potom disertacija na temu dubrovačkog slikarskog kruga Antuna Karamana ${ }^{6}$ te $_{\text {knjiga }}{ }^{7}$ i magistarski rad o likovnoj kritici i izložbama u Dubrovniku od I877. do I977. godine. ${ }^{8}$ Ipak, postoji još niz umjetničkih imena, domaćih i stranih slikara dubrovačkoga područja koji zasigurno zaslužuju opširnije studije u budućnosti.

Povijest umjetničkih izložbi u Dubrovniku slična je povijesti izložbi u našim većim gradovima: u nedostatku specijaliziranih izložbenih prostora u drugoj polovini Ig. stoljeća, umjetnici se publici predstavljaju u izlozima trgovina na Stradunu, ali i prostorima općinske kavane i općinske dvorane. Izlozi na

\section{Sanja Žaja Vrbica}

Odjel za umjetnost i restauraciju Sveučilište u Dubrovniku sanja.vrbica@unidu.hr

https://orcid.org/oooo-oooI-625I-I509
I KRUNO PRIJATELJ, Slikarstvo u Dalmaciji I784-I884, Split, I989., 5-29. U knjizi su obrađeni slikari prve polovine rg. stoljeća u Dubrovniku.

2 GRGO GAMULIN, Hrvatsko slikarstvo XIX. stoljeća, prvi svezak, Zagreb, I995., I67-I78; GRGO GAMULIN, Hrvatsko slikarstvo na prijelazu iz XIX. u XX. stoljeće, drugi svezak, Zagreb, I995., 43, 242, 350-38I; GRGO GAMULIN, Hrvatsko slikarstvo XX. stoljeća, prvi svezak, Zagreb, I997., 327-335; GRGO GAMULIN, Hrvatsko slikarstvo XX. stoljeća, drugi svezak, Zagreb, I997., I28- I63.

3 VINICIJE LUPIS, O sakralnoj baštini uoči pada Republike i u prvim desetljećima I9. st. u Dubrovniku i okolici, u: Peristil, 49 (2006.), Io7- I28.

4 TONKO MAROEVIĆ, Slikarstvo u Hrvatskoj u XIX. stoljeću, u: Hrvatska i Europa, Moderna hrvatska kultura od preporoda do moderne, (ur.) Mislav Ježić i dr., Zagreb, 2009., 5I $7-523$.

5 LUCIJA ALEKSIĆ, Dubrovačko slikarstvo od Igoo. -I945., ANTUN KARAMAN, Uvod, VERA KRUŽIČ UCHYTIL, Počeci moderne umjetnosti u Dubrovniku, sve u: roo godina moderne umjetnosti u Dubrouniku, katalog izložbe, Umjetnička galerija Dubrovnik, Dubrovnik, ı978., bez pag.

6 ANTUN KARAMAN, Kolorizam dubrovačkog slikarskog kruga, doktorska disertacija, Sveučilište u Zagrebu, I997., I-I36.

7 ANTUN KARAMAN, Kolorizam dubrovačkog slikarskog kruga, Zagreb, 2007., 9-10, 22-25, 33-36.

8 SANJA ŽAJA VRBICA, Likovna kritika i izložbe u Dubrovniku I876.- I978., magistarski rad, Sveučilište u Zagrebu, Centar za postdiplomske studije u Dubrovniku, Dubrovnik, I999., I7-35, 40-6I. 
Stradunu kao izložbeni prostori bili su doduše skučeni, ali su imali i veliku prednost izravna kontakta s publikom. Stradun je tijekom druge polovine I9. stoljeća i do početka Drugoga svjetskog rata bio epicentar društvenog života Dubrovnika, živo okupljalište svih struktura gradske populacije i turista, premda se grad potkraj Ig. stoljeća počinje širiti na područja izvan gradskih zidina.

Podataka iz sredine ig. stoljeća o umjetnicima je malo, tek u šestom i sedmom desetljeću ističe se manji broj slikara koji rade u Dubrovniku i na dubrovačkom području ili tu povremeno ili dulje borave: Petar Franjo Martecchini, Zebedeo Piccini, Jaroslav Čermak, koji posjeduje vlastitu kuću u Župi dubrovačkoj. Izdavač Petar Franjo Martecchini ${ }^{9}$ bavio se crtanjem i akvarelima, Zebedeo Piccini ${ }^{10}$ vrlo je aktivan u Dubrovniku tijekom šezdesetih i sedamdesetih godina Ig. stoljeća, osobito na opsežnim radovima obnove katedrale. Pored katedrale, gdje je evidentiran kao slikar i dekorativni slikar, ali i restaurator, Piccini radi zidne slike u ljetnikovcu Crijević-Pucić na Pilama, u srpskoj pravoslavnoj crkvi sv. Blagovještenja, u prezbiteriju crkve Gospe od Karmena te oltarnu palu za crkvu sv. Stjepana u Sustjepanu. Godine I878. Slovinac Jaroslavu Čermaku, preminulu te godine, posvećuje veći članak s nizom biografskih podataka, navodeći i Čermakove posjete Dubrovniku I858. godine, u potrazi za živopisnim folklornim kostimima, potom ponovo I86I. s mladim češkim slikarom Josefom Huttaryjem te još jednom I862. godine. U Župi dubrovačkoj pored Dubrovnika Čermak je često boravio u svojoj kući i ondje naslikao slike Hercegovačka obitelj, Župski konjušar s konjima i Portret župnika Dum Marina Beusana, a iz Župe je odlazio i na Cetinje, slikati vladarsku obitelj. ${ }^{11}$ U Dubrovnik i okolicu povremeno navraćaju brojni strani slikari, poput poznatoga bečkog pejzažista Emila Jakoba Schindlera, koji dolazi I874., I887./I888. i I89o. godine ${ }^{12}$ te tijekom svog drugog posjeta upoznaje i mladoga Mata Celestina Medovića, kojeg preporuča profesoru Löfftzu na minhenskoj Akademiji, kamo je Medović uskoro i otputovao na školovanje. ${ }^{13}$

Sedamdesetih godina umjetnički se život u Dubrovniku postepeno intenzivira, Mato Celestin Medović i Vlaho Bukovac počinju svoju umjetničku edukaciju. Upravo je Bukovčevo predstavljanje dubrovačkoj javnosti i jedan od najranijih spomena izložbi. Dobro poznati uzvik „Habemus pictorem” Meda Pucića I876. godine u ljekarni Rafa Šarića u Dubrovniku ${ }^{14}$ ilustrira želju za vlastitim slikarom, ali i vjerojatno ustaljenu praksu izlaganja slika u prostorima na Stradunu. Razmatranje tog poglavlja dubrovačke umjetnosti dodatno otežava nedostatak lokalnih novina, jer će nakon gašenja lista L'Avvenire I849. godine proći čak trideset i tri godine do izlaska sljedećega političkog lista, ${ }^{15}$ a upravo su lokalne novine i časopisi izvori dragocjenih podataka o umjetnicima aktivnim u Dubrovniku.

Prvi podaci o izložbama u drugoj polovini ig. stoljeća javljaju se dakle s pojavom štampe. List Slovinac, s podnaslovom „List za knjigu, umjetnost i obrtnost", koji je naglašavao i njegovu orijentaciju, izlazi od I878. do I884. godine. U rubrici Sitnice list sporadično donosi i obavijesti o likovnim umjetnicima, koje ljeća Petar Franjo Martecchini, kao crtač, akvarelist i ljubitelj starina, u: Prilozi povijesti umjetnosti u Dalmaciji, I (I957.), 233, 236-249.

IO IVAN VIĐEN, Druga polovina Ig. stoljeća: između dvije velike obnove i stalnog nastojanja oko uređenja (I855.-1876.), u: Katedrala Gospe Velike u Dubrouniku, (ur.) Katarina Horvat Levaj, Dubrovnik-Zagreb, 20I4., $45^{2}, 47 \mathrm{I}, 472$.

II -, Jaroslav Čermak, u: Slovinac, 2 (I878.), I5, I6. O Jaroslavu Čermaku u Dubrovniku piše i Josip Bersa: JOSIP BERSA, Dubrovačke slike i prilike (I80o.-I88o.), Dubrovnik, 2002., I42, I54.

I2 IRENA KRAŠEVAC, Motivi Dubrovnika u opusu austrijskog slikara Emila Jakoba Schindlera, u: Radovi Instituta za povijest umjetnosti, 39 (20I5.), IIо.

I3 MATO CELESTIN MEDOVIĆ, Autobiografija, Kuna na Pelješcu, 20I5., 63. Na svom putu u München Medović je u Plankenburgu bio gost E. J. Schindlera dva dana. I4 JOSIP BERSA, (bilj. II), 236 .

I5 IVO PERIĆ, Dubrovačka periodika I848.-I94I., Dubrovnik, I980., I4-I6. 
su nam danas posebno dragocjene kao najstariji izvor informacija o javnim prezentacijama suvremenih likovnih djela u Dubrovniku.

Tijekom I879. godine Slovinac je zabilježio izlaganje jedne Bukovčeve slike (Crnogorka sa sviralom) u Općinskoj kavani: "G. Bukovac donese je sa sobom ove godine doma i evo ima nekoliko dana objesi je u općinsku Kafanu da na palogu stoji." Uz tu obavijest nalazi se i citat preporuke Bukovčeva profesora Alexandrea Cabanela. ${ }^{16}$ Te godine časopis navodi i jednog novog slikara, Nika Nardellija, koji kopira sliku Miha Vilenika darovanu Domorodnom muzeju te iznosi i nadu za mogućnost školovanja mladog talenta. ${ }^{17}$ Iste godine urednik Slovinca Luko Zore predstavlja čitateljima mladoga Vlaha Bukovca: „Evo danas napokon možemo našijem štiocima da prekažemo jednu vojku u našoj gradini niklu, ali samoniklu a ne presagjenu iz tugje zemlje." Napis jasno izražava postojanu želju za vlastitim, školovanim umjetnicima, što se dodatno ističe i u zaključku članka, gdje autor priželjkuje još mladih umjetnika u Dubrovniku, spominjući kao talente Nika Nardellija i Mata Celestina Medovića te raspravljajući o mogućnostima njihova školovanja, odnosno pozdravljajući Bukovčevu stipendiju Zemaljskog odbora: „Samo nijesmo radi da na tomu sve svrši, jer bi prava grehota bila da naš mladi slikar prekine svoj tečaj, i pogje trbuhom za kruhom." ${ }^{\text {18 }}$

Trajnu želju za vlastitim stvarateljima ilustrira i članak Nika Lepeša naslovljen Pet slikara Dubrovačkijeh. Autor ističe Miha Vilenika, koji se afirmirao u Parizu, ali ga na osnovi dubrovačkog podrijetla obitelji autor ubraja u lokalne umjetnike, potom Vlaha Bukovca, Nika Nardellija, amatera često spominjana u Slovincu, tada mlada franjevca Mata Celestina Medovića na školovanju u Rimu te Nika Zeca iz Župe Dubrovačke. Taj slikar poslije se ne spominje u Dubrovniku jer već u vrijeme pisanja članka živi u Bostonu, gdje je dobio slikarsku naobrazbu i otvorio vlastiti atelijer, no autoru je važan radi dubrovačkog ishodišta. $^{19}$

Zanimljivi su članci Meda Pucića, poznatoga mecene Vlaha Bukovca, jer njegova nastojanja afirmacije dubrovačkih likovnih umjetnika ne završavaju s prepoznavanjem talenta Vlaha Bukovca i Bukovčevim odlaskom u Pariz, već on kontinuirano prati Bukovčev umjetnički razvoj, slikarske zadatke te izložbe izvan Dubrovnika. Na Pariškom salonu i878. godine pronalazi u katalogu i ime afirmiranoga francuskog marinista dubrovačkog porijekla Miha Vilenika te na nekoliko stranica Slovinca izvještava o njegovim umjetničkim uspjesima. Također donosi detaljne opise Pariškog salona te upoznajući čitatelje s tom važnom umjetničkom manifestacijom nastoji senzibilizirati dubrovačku javnost na potrebu organiziranja izložbi, prepoznavanja i podupiranja likovnih talenata. ${ }^{20}$ Nekoliko godina poslije Medo Pucić umire, a u opširnom nekrologu naglašena je upravo autorova angažiranost na polju likovnih umjetnosti. Pišući da je bio „gentleman u pariškom salonu, gospar u dubrovačkom krugu" autor članka ističe Pucićev kozmopolitski duh te posebno izdvaja njegov senzibilitet za likovne umjetnosti na osnovi kojeg je prepoznao i talent mladoga Bukovca te ga
I6 -, Naš mladi slikar Bukovac, u: Slovinac, I9 (I879.), 304 .

I7 -, Novi slikar, u: Slovinac, 7 (I879.), II2.

I8 Z [Luko Zore], Umjetnost, u: Slovinac, I5 (I879.), 233.

I9 Ndr. L [NIKO LEPEŠ], Pet slikara Dubrovačkijeh, u: Slovinac, 20 (I88I.), 422.

20 MEDO PUCIĆ, Umjetnost. Miho Vilenik slikar u Parizu, u: Slovinac, 2 (I878.), I3, I4 
poveo na parišku akademiju. Osim Bukovca, Pucić je dubrovačkoj publici „otkrio” i Miha Vilenika te Petra Mančuna, rimskoga grafičara dubrovačkog podrijetla, pa autor zaključuje o stalnoj pozornosti upućenoj umjetnicima: „Uopće pak sve što je služilo da se razglasimo, on je podupirao i vriježio neprestanom pažnjom i budnosti."

Nakon Slovinca u Dubrovniku se I89i. pojavljuje tjednik Crvena Hruatska, a sljedeće godine i list Dubrounik, oba s rubrikama posvećenim gradskim vijestima, gdje su često bilježene izložbe. Novine tako izvještavaju o izložbama u Dubrovniku, ali prate i izložbe dubrovačkih umjetnika u Beču, Londonu, Parizu, Ljubljani. Umjetnine se pak izlažu u izlozima ljekarne Šarić, zlatarne Bibica, dućana Stjepana Bravačića i Mitrovića, tiskare De Giulli, u općinskoj kavani, u općinskoj dvorani, u Čitaonici i Sokolani, koja se tada nalazila u Sponzi. U tim godinama javlja se niz umjetnika: Vlaho Bukovac, Marko Murat, Mato Celestin Medović, amaterski slikari Ivo Skatolini i slikarica Dome Suhor, studenti venecijanske akademije Frano Radovani i Josip Vučetić te venecijanski slikar Vincenzo Faggiotto. ${ }^{22}$

Zanimljive su i upute potencijalnim turistima iz Baedekerovih vodiča tog doba. Među različitim znamenitostima turistima se preporučuje posjet katedrali s bogatim sakralnim opusom, ali i Domorodnom muzeju. U vodiču iz I89. godine ${ }^{23}$ Općinska palača i Knežev dvor spominju se kao jedna zgrada, s muzejom. Godine Igoo $^{24}$ ti su podaci korigirani, pa se Općinska palača spominje kao građevina iz I862. godine, s kavanom i teatrom, te Museo Patrio na drugom katu, gdje se nalazi zbirka antikviteta i prirodoslovnog materijala, za posjetitelje, otvorenima nedjeljom i srijedom od Io do I2 sati, uz napomenu da se za strance i ostalim danima mogu organizirati posjeti.

Godine I9o6. spominje se dućan, odnosno papirnica nasljednika Bernharda Weissa na Pilama, jer mladi Todor Švrakić, Bukovčev praški student, na proputovanju kroz Dalmaciju boravi u Dubrovniku te prima narudžbe za portrete u tom dućanu. ${ }^{25}$ Kao prodajno mjesto umjetnina papirnica Weiss i Damiani na Pilama se ponovo spominje i I9i3. godine, kada je nadvojvotkinja Windischgrätz ondje kupila sliku marine kapetana E. Radelje, pa zaključujemo da je očito riječ o prostoru koji trajno izlaže djela različitih slikara, studenata slikarstva i amatera. ${ }^{26}$ Ako je suditi prema oglasu papirnice Weiss iz I925., u kojem se 1877. godina spominje kao godina utemeljenja, moguće je da su se već od prvih godina ondje prodavale i umjetnine. ${ }^{27}$

Okolnosti umjetničkog razvoja dubrovačkih mladih likovnih talenata na prijelazu stoljeća najbolje ocrtava članak Arsena Wenzelidesa iz I9o3. posvećen tada dvadesetogodišnjem Marku Rašici. Autor je člankom želio afirmirati Rašicu, mladog amatera, upozoriti i potaknuti potencijalne mecene na pomoć samozatajnom umjetniku i omogućiti mu školovanje, ali nam otkriva i prepreke s kojima se susreću mladi umjetnici u dubrovačkoj sredini-organiziranje izložbi iziskuje troškove, najam prostora foajea dubrovačkog kazališta s cijenom od roo kruna mnogima je nedostižan, vijećnici nemaju sluha za probleme mladih slikara, a nedostaje i kompetentnih likovnih kritičara. ${ }^{28}$
2 I -, Medo knez Pucić, u: Slovinac, 23 (I882.), 36ı, 362 22 SANJA ŽAJA VRBICA (bilj. 8), I7-20.

23 Southern Germany and Austria Including Hungary, Dalmatia and Bosnia. Handbook for Travelers by $K$. Baedeker, Leipzig-London, I89I., 44I, 442.

24 Austria, Including Hungary, Transylania, Dalmatia and Bosnia. Handbook for Travelers by Karl Baedeker, Leipzig-London-New York, I9oo., 309, 3Iо.

25 -, Gjak slikarske praške akademije u Dubrovniku, u: Crvena Hrvatska, 3I (Igo6.), 5.

26 -, Slika E. Radelje, u: Crvena Hrvatska, 22 (I9I3.), 3.

27 -, Papirnica B. Weiss nasljednici-utem. I877. g. Dubrovnik, u: Hruatska riječ, 24 (I925.), I5.

28 Arsen Wenzelides, Mladi slikar Marko Rašica, u Hruatska kruna, 30 (I903.), I. 
Godine I9o8. tijekom travnja održana je umjetnička izložba u općinskoj dvorani. U dubrovačkim novinama najavljena je kao prva umjetnička izložba otvorena u Dubrovniku, sa iıo izloženih radova, od kojih dio izlažu domaći umjetnici Josip Vučetić i Josip Lalić, nekoliko čeških slikara, između kojih Václav Špála, Bedřich Feigl, Emil Filla, ${ }^{29}$ potom engleski slikar pogrešno naveden kao Albert Silian Percy ${ }^{30}$ te Bukovčevi studenti. Izložba je bila prodajna, a polovica prihoda namijenjena je Društvu za poljepšanje Dubrovnika, no čini se da je odaziv domaće publike bio slab jer novine naglašavaju veliku zainteresiranost stranih posjetitelja u odnosu na nezainteresiranost domaće sredine ${ }^{31} \mathrm{U}$ siječnju iste godine Marko Rašica u otvorenom pismu dalmatinskim zastupnicima i umjetnicima, želeći ih potaknuti na aktivnije sudjelovanje u zahtjevima povećanja proračuna za umjetnost i kulturu, definira nekoliko ciljeva. Poznavajući umjetničke prilike u Dalmaciji apelira na traženje umjetničkih potpora, gradnju umjetničkog paviljona u Dalmaciji, otvaranje umjetničkog muzeja ili galerije te prenamjenu Kneževa dvora u Dubrovniku u galeriju. No, ohrabren bečkim iskustvima, savjetuje i prenošenje planirane izložbe (Prva dalmatinska umjetnička izložba, otvorena u listopadu I9o8.) u Zadar i Dubrovnik, kao i dalje u Češku i Poljsku, radi afirmacije naše umjetnosti i izvan granice Hrvatske te uspostave kontakata s ostalim slavenskim narodima. ${ }^{32}$

Nakon Prvoga svjetskog rata okolnosti su postale povoljnije, otvara se Salon Weiss na Stradunu, spominjan i prije, od Igo6., kao papirnica na lokaciji na Pilama, a od I9I3. pod nazivom Weiss i Damiani. Oglasom u listu Dubrounik najavljeno je otvaranje privatnog izložbenog salona s nazivom Mali umjetnički salon Weiss I. listopada I923. te oglašeno dvokratno radno vrijeme, radnim danima od 9 do I2 i I6 do 20, a praznicima od 9 do II sati, kao i podatak o slobodnom ulazu. ${ }^{33}$ Taj će salon kontinuirano održavati vrlo živu izložbenu djelatnost, a dubrovački tjednici redovito upozoravaju na njegove izložbe (sl. I, sl. 2). Godine rg24. u Salonu Weiss organizirana je izložba tridesetak radova ruskog umjetnika nastanjena u Dubrovniku Alekseja Vasiljeviča Hansena, ${ }^{34}$ I925. ondje izlažu dvije bečke umjetnice, Frieda Salvendy i Katharina Zirner, ${ }^{35}$ a r926. ondje je organizirana izložba slika u emajlu austrijske slikarice Marije Cyrenius i slika njemačkog slikara Maxa Peiffera Watenphula ${ }^{36}$ Dvojezični natpisi na plakatima izložbi ukazuju i na ciljanu publiku, jer očito su brojni turisti koji borave $u$ gradu kupovali i umjetnine. No činjenica da se u blizini Salona Weiss nalazila i već spomenuta papirnica iste tvrtke, kao i novinski oglasi o prodaji muzičkih instrumenata i opreme, trgovačkih knjiga i pisaćih strojeva te povremeno i božićnog nakita na istom mjestu, ${ }^{37}$ jasno ilustrira činjenicu da prodaja umjetnina nije donosila sigurnu dobit.

Međuratno je razdoblje doba intenzivnih umjetničkih aktivnosti, povećava se broj izlagača i prostora namijenjenih izložbama. Tada je izlaganje umjetnina u izlozima dućana rjeđe, a dominiraju izložbe u većim i prikladnijim dvoranama. Sponza je vraćena gradskoj upravi i postaje atraktivni izložbeni prostor,
29 Novine navode Fillino ime kao Milon, a ne Emil. Emil Filla (I882.- I953.), usp. Allgemeines Künstler-Lexikon, München-Lepizig: K. G. Saur, Bd. 40, 4I-45.

30 Moguće je da se radi o slikaru Herbertu Sidneyju Percyju (I863.-I932.), sinu slikara pejzažista Sidneyja Richarda, usp. Allgemeines Lexikon der bildenden Künstler, Ullrich Thieme-Felix Becker / Hans Vollmer, Leipzig: E. A. Seemann, Bd. 26, 396.

3I SANJA ŽAJA VRBICA (bilj. 8), 8, I9.

32 [Marko Rašica], Nekoliko riječi dalmatinskim zastupnicima i umjetnicima, na uvaženja, u: Hrvatska kruna I6 (I908.), I8.

33 SANJA ŽAJA VRBICA, (bilj. 8), 4I;-, Mali umjetnički salon Weiss-Dubrovnik, u: Dubrounik, 26 (Ig23.), 2.

34 -, Mali umjetnički salon B. Weiss i nasljed., Izložba slika prof. A. Hansena, u: Dubrovački list, I5 (I924.), 6.

35 L, Slikarska izložba u salonu Weiss, u: Dubrovački list, 27 (I925.), 2.

36 -, Mala izložba caklinskih (Emajl) radnja iz ateliera slikarice gospođe Marije Cyrenius i slikara g. Maksa Watenphula iz Salzburga, u: Hrvatska riječ, 37 (I926.), 4 .

37 -, Papirnica B. Weiss nasljednici-utem. I877. g. Dubrovnik, u: Hrvatska riječ, 24 (I925.), I5.;-, Muzičkih instrumenata u bogatom izboru, u: Hrvatska riječ, 37 (เ926.), 4 . 

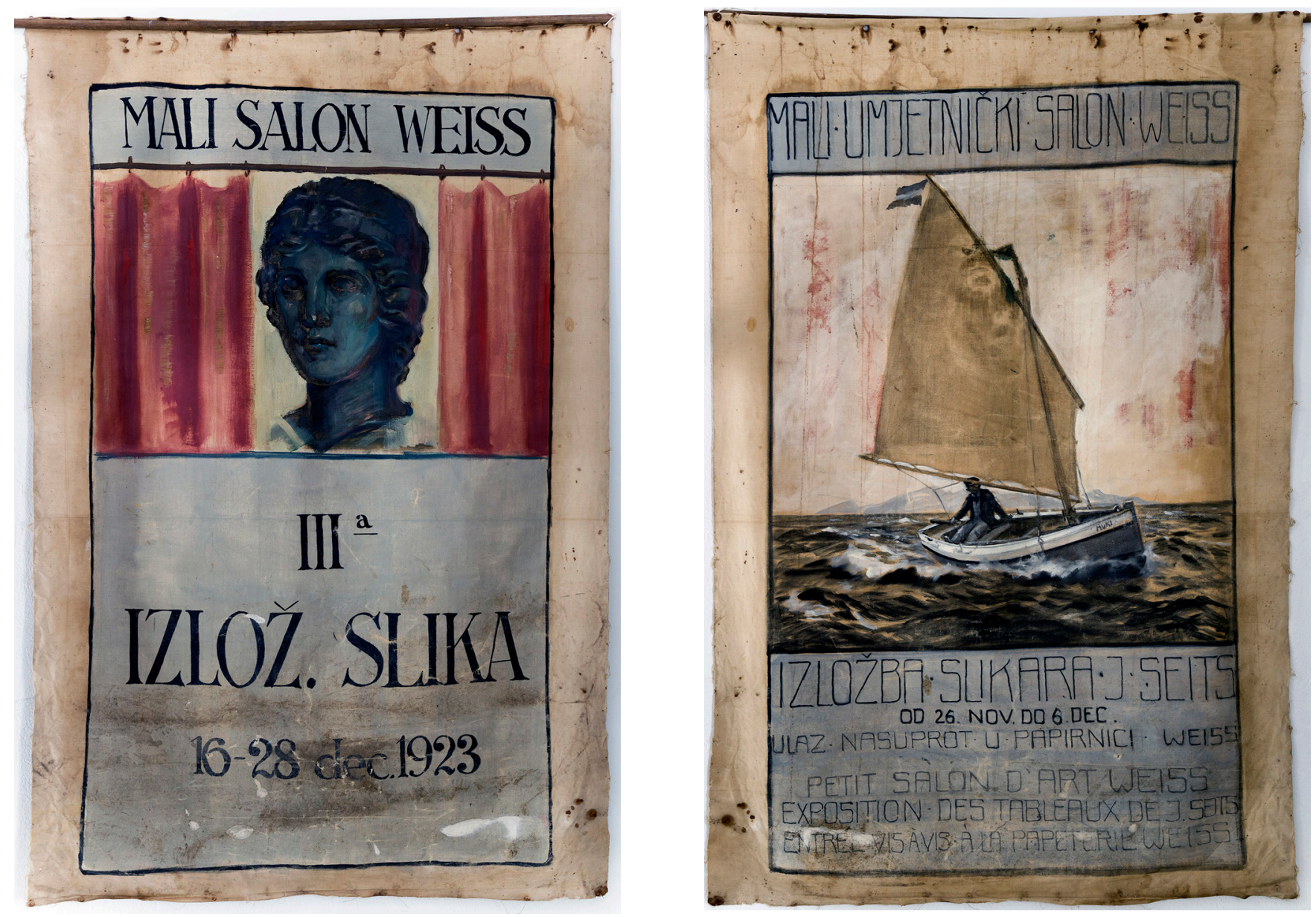

otvara se dvorana Ženske narodne udruge, koja okuplja i prve dubrovačke slikarice, općinska vijećnica već otprije ima ulogu važnog izložbenog središta. Uoči Drugoga svjetskog rata otvara se i muzej Rupe. Broj umjetničkih imena na izložbama također se povećava, pored domaćih često srećemo njemačke, češke, austrijske i ruske umjetnike. ${ }^{38}$ Neki od njih žive u Dubrovniku poput Alekseja Hansena ${ }^{39}$ i Johanna Seitsa, ${ }^{40}$ ili tu provode zime, poput Oszkára Mendlika, ${ }^{41}$ nizozemskog slikara mađarskoga podrijetla. Oko Koste Strajnića okuplja se krug mladih darovitih slikara, od kojih će neki poslije postati istaknuti, afirmirani umjetnici, poput Božidara Rašice, Josipa Collone, Antuna Masle i Ive Dulčića. ${ }^{42}$

Tih godina novine bilježe i izložbe izvan najužeg dijela Dubrovnika: I927. je u kući Jaroslava Čermaka u Srebrenom izložena serija dubrovačkih motiva, uz napomenu da je izložba „odlično posjećena od strane publike", ${ }^{43}$ a I933. godine bilježimo i prvu izložbu u Lapadu. U svojoj kući amaterska slikarica Flora Jakšić otvara izložbu veziva i goblena te slike krajolika, koje su posjetitelji mogli vidjeti svakodnevno od 9 do I2 i od I6 do
Slika I

Plakat Malog salona Weiss, I923. Umjetnička galerija Dubrovnik, foto: Darko Vrbica

Slika 2

Plakat Izložbe J. Seitsa, Mali salon Weiss, I923.

Umjetnička galerija Dubrovnik, foto: D. Vrbica

$3^{8}$ SANJA ŽAJA VRBICA (bilj. 8), 40-42.

39 -, Mali umjetnički salon B. Weiss i nasljed., Izložba slika prof. A. Hansena, u: Dubrovački list, I5 (I924.), 6. 40 SANJA ŽAJA VRBICA, Johann Seits, katalog izložbe, (ur.) Antun Maračić, Dubrovnik, 2004., 32.

4I SANJA ŽAJA VRBICA, Marko Rašica, Zagreb, 20I4., 25. 42 ANTUN KARAMAN (bilj. 7), 25.

43 -, Slikar g. Jože Mikša, u: Dubrovački list, 27 (1927.), 2. 
I8 sati. ${ }^{44}$ Slikarica je kuću oporučno ostavila dubrovačkim umjetnicima te se u njoj danas nalazi galerija Hrvatskog društva likovnih umjetnika u Dubrovniku, Galerija Florin dom. U Cavtatu je 1938. u Domu sv. Nikole otvorena izložba sakralnih slika, među kojima je i Bukovčev Isusov grob. ${ }^{45}$

Zahtjevi za otvaranjem umjetničkog muzeja u međuratnom razdoblju postaju sve učestaliji. Poznata je uloga likovnog kritičara Koste Strajnića, koji dolazi u Dubrovnik na mjesto konzervatora I928. godine te piše o potrebi otvaranja umjetničke galerije. ${ }^{46}$ Pored apela Koste Strajnića, javljaju se i drugi glasovi. Ivo Kolbe, pravnik i publicist, u članku Za dubrovački galeriju slika, Apel koji valja potpomoći pokušava potaknuti sugrađane na osnivanje umjetničke galerije. Po njemu bi Knežev dvor trebalo pretvoriti u gradski muzej, s namještajem i portretima iz doba Republike, darovima sugrađana, ali i galerijom suvremenih umjetnika, koji bi, smatra, rado ustupili svoje radove, što su mu potvrdili Dobrović, Hansen i Rašica, te bi se tako bez troškova za desetak godina stvorila respektabilna zbirka. ${ }^{47}$

Potkraj I9. stoljeća nastala je i intenzivno rasla zbirka Domorodnog muzeja, i to isključivo donacijama građana, tako da nije bilo neobično očekivati da će se i zbirka jednog novog umjetničkog muzeja popunjavati na taj način. Po završetku Drugoga svjetskog rata, u prosincu i945. godine otvorena je Umjetnička galerija Dubrovnik, u prostoru ljetnikovca Crijević-Pucić na Pilama, a za njezino otvaranje zaslužan je Kosta Strajnić, prvi direktor Galerije. Na otvaranju su izložena posuđena djela iz drugih muzeja, ali i dubrovačkih umjetnika iz privatnih zbirki. U Knežev dvor useljen je Domorodni muzej, a za posjetitelje je otvoren I950. godine. Veliki broj predmeta muzeja i današnjeg stalnog postava darovi su dubrovačkih obitelji.

Premda ne postoje javni specijalizirani izložbeni prostori do I945. godine, likovni život Dubrovnika možemo kontinuirano pratiti od druge polovine ig. stoljeća. Izložbe održavane u izlozima trgovina na Stradunu i ostalim prostorima bile su ponajprije komercijalnog karaktera, no omogućile su domaćim i stranim umjetnicima živu komunikaciju s publikom te su u nekoliko slučajeva rezultirale općinskim stipendijama, nužnima za odlazak na školovanje na neku od akademija. Prate ih novinski izvještaji, tek rijetko i likovne kritike, pa možemo zaključiti da su te prve izložbe kontinuitetom i raznolikošću te internacionalnim karakterom potaknule uspostavljanje muzejskih institucija i namjenskih galerijskih prostora, preteča današnjih glavnih umjetničkih i muzejskih ustanova u Dubrovniku. S katalogom različitih umjetnika koji su se na njima izmjenjivali one pak čine zanimljivu dionicu dubrovačke i hrvatske likovne umjetnosti.

\section{() (1)}

Likovni život u Dubrovniku između ı85o. i ı945. godine / Sanja Žaja Vrbica / CC $\mathrm{BY} / 4.0$

DoI: https://doi.org/Io.3I664/z4khpu.34
44 -, Izložba g.je Flore Jakšić, u: Narodna svijest, 22 (I933.), 3.

45 -, Izložba slika u Cavtatu, u: Narodna svijest, 3 o (I938.), 3 .

46 SANJA ŽAJA VRBICA, Za umjetničku aktivnost Dubrovnika, u: Kosta Strajnić život i djelo, (ur.) Ivan Viđen, Dubrovnik-Zagreb, 2009., Ig.

47 IVO KOLBE, dr., Za dubrovačku galeriju slika, Apel, koji valja potpomoći, u: Novosti, 235 (I933.), I3. 